
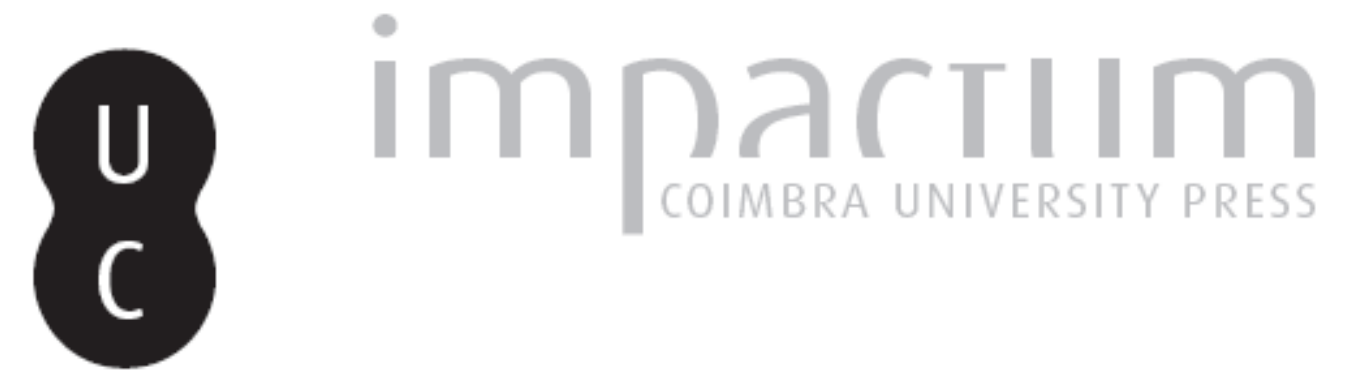

\title{
Arqueologia no Saara: uma aproximação ao deserto
}

\section{Autor(es): Braga, Sofia Fonseca}

Publicado por: Faculdade de Letras da Universidade de Coimbra

URL persistente:

URI:http://hdl.handle.net/10316.2/37736

DOI:

DOI:http://dx.doi.org/10.14195/1647-8657_45_19

Accessed : $\quad$ 26-Apr-2023 10:55:51

A navegação consulta e descarregamento dos títulos inseridos nas Bibliotecas Digitais UC Digitalis, UC Pombalina e UC Impactum, pressupõem a aceitação plena e sem reservas dos Termos e Condições de Uso destas Bibliotecas Digitais, disponíveis em https://digitalis.uc.pt/pt-pt/termos.

Conforme exposto nos referidos Termos e Condições de Uso, o descarregamento de títulos de acesso restrito requer uma licença válida de autorização devendo o utilizador aceder ao(s) documento(s) a partir de um endereço de IP da instituição detentora da supramencionada licença.

Ao utilizador é apenas permitido o descarregamento para uso pessoal, pelo que o emprego do(s) título(s) descarregado(s) para outro fim, designadamente comercial, carece de autorização do respetivo autor ou editor da obra.

Na medida em que todas as obras da UC Digitalis se encontram protegidas pelo Código do Direito de Autor e Direitos Conexos e demais legislação aplicável, toda a cópia, parcial ou total, deste documento, nos casos em que é legalmente admitida, deverá conter ou fazer-se acompanhar por este aviso.

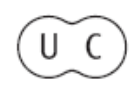




\section{CONIMBRIGA}

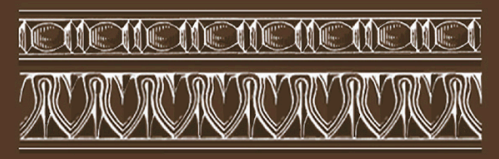

INSTITUTO DE ARQUEOLOGIA

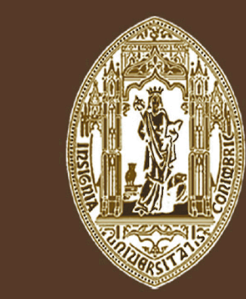

VOLUME XLV - 2006

FACULDADE DE LETRAS UNIVERSIDADE DE COIMBRA 
Sofia FonseCa BRAga

Doutoranda de Egiptologia da Universidade Autónoma de Barcelona e da Universidade Nova de Lisboa

\section{ARQUEOLOGIA NO SAARA: UMA APROXIMAÇÃO AO DESERTO "Conimbriga" XLV (2006) p. 359-375}

RESUMO: O Saara é o maior deserto árido do mundo e uma imensa estação arqueológica. As transformações climáticas, pelas que passou esta região da terra, desenharam a sua fisionomia física e humana, e conferiram, à arqueologia do deserto, um carácter e metodologias próprias.

RESUMEN: El Sahara es el más grande desierto árido del Mundo y una inmensa estación arqueológica. Los cambios climáticos por los que paso esta región de la tierra, dibujaron sus contornos geográficos y humanos, y le dieron, a la arqueología del desierto, un carácter y metodologías propias. 
(Página deixada propositadamente em branco) 


\section{ARQUEOLOGIA NO SAARA: UMA APROXIMAÇÃO AO DESERTO}

“(...) Y cuando más de uno me pregunta qué provecho puede aportar

a la humanidad el conocimiento de un mar yermo de roca y arena, el hallazgo de algunas insignificantes manchas de vegetación o de una fuente con agua desabrida, y por qué se hacen sacrificios materiales y se corren riesgos personales por tales descubrimientos, no puedo dar otra respuesta que el proverbio beduino: "El desierto es terrible e implacable, pero quien lo haya conocido tendrá que regresar de nuevo a él".

Ladislau Almásy. 1999. Nadadores en el Desierto. Barcelona: Península: 220.

Falar de arqueologia no Saara passa obrigatoriamente por conhecer a evolução climática que sofreu esta região da Terra. Se a ocupação humana de qualquer região passa pela adaptação às condições climáticas e ao ecosistema que a envolve, nas geografias de clima extremo, como o deserto do Saara, essa adaptação está ainda mais ligada às mudanças climáticas que aí ocorreram ao longo do tempo. Para compreender a ocupação humana e, em consequência, a arqueologia do Saara temos primeiro que conhecer essa imensa região, que ocupa cerca de $8.000 .000 \mathrm{~km} 2$ e que representa o maior deserto quente do mundo (Nantet, B., 1999: 209)1.

Ao contrário da imagem que muitas vezes temos do deserto, e neste caso do Saara, a maior parte da sua superficie não é ocupada por imensas sequências de dunas, os chamados Ergs. Pelo contrário, as cadeias dunares representam apenas uma quarta parte de toda a sua

1 As precipitações rondam os $100 \mathrm{~mm}$ anuais e em algumas regiões não passam dos 20 mm (Vernet, R., 1995: 12). A região mais árida do Saara está no Egipto, no Grande Mar de Areia onde podem cair apenas 5 mm anuais (Muzzulini, A., 1995: 12). 
extensão ${ }^{2}$. A fisionomia do deserto compõe-se de uma variedade assombrosa de geografias e paisagens que quebram a suposta monotonia do terreno: vastas planícies pedregosas conhecidas como Hamadas ou Regs, que ocupam a maior parte do território; os Tassili ou Djebel ${ }^{3}$, cadeias montanhosas que salpicam o mapa do Saara e onde se concentra a maior parte da arte rupestre da região (fig. 1); os Oued ou rios secos, onde de forma temporal pode surgir água que permite a aparição de vegetação e fauna; as Sebkhas, fundos salgados de antigos lagos; os Oásis que marcam não só a fisionomia mas também a história da ocupação humana da região, uma vez que foram, e continuam a ser, os únicos refúgios onde a vida humana foi sempre possível (Fonseca Braga, S., 2002: 11).

Para além destes aspectos relativos à fisionomia do deserto, há importantes fenómenos a ter em conta na formação do mesmo, como as mudanças térmicas diárias e o vento.

A variação térmica que ocorre diariamente é um dos principais factores de alteração da paisagem. Não se trata tanto do grau de variação, mas da rapidez com que ocorre: podemos falar de variações de entre $15^{\circ}$ e $20^{\circ}$ de temperatura numa questão de horas ou até mesmo minutos (Sers, J.-F., 1994: 28-29). Isso leva a que as rochas sofram grandes choques térmicos que conduzem à aparição de linhas de ruptura que, por sua vez, acabam por esculpir formas que muitas vezes parecem feitas por mãos humanas.

Mas talvez seja o vento o fenómeno com o papel mais destacado na arqueologia do Saara. É ele o grande responsável pela erosão constante da paisagem, que implica que as estações arqueológicas sejam, quase exclusivamente, estações de superfície. Isto significa por um lado, que a presença de estratigrafia é praticamente inexistente, aparecendo as estruturas e o material arqueológico à superficie e, por outro lado, que uma estação possa desaparecer de um ano para o outro debaixo de uma duna

2 A única excepção está provavelmente no Saara mauritano composto por $80 \%$ de dunas e areia (Vernet, R., 1995: 10) que é afinal, o "último estado da rocha" (Vivian, C., 200: 10).

3 As principais cadeias montanhosas do centro do Saara são: o Tassili N'Ajjer (Argélia), o Hoggar (Argélia), o Tibesti (Chade), o Adrar dos Iforas (Argélia e Mali) e o Air (Níger). Mas não podemos também deixar de referir o Ennedi (Chade), o Djebel Uweinat e o Gilf Kebir no Saara líbico (Egipto) como importantes centros de arte rupestre saariana. 
móvel. ${ }^{4}$ Por exemplo, uma Bashandie ou Barchan, pode chegar a deslocar-se mais de 7,5 m por ano, alcançar entre 30 e $40 \mathrm{~m}$ de altura e ter mais de $200 \mathrm{~m}$ de largura (Sers, J. F., 1994: 19-23)!

Claro que esta descrição do Saara corresponde à actualidade. É a descrição de um deserto que se formou definitivamente no Quaternário, como consequência do aumento da aridez deste período geológico, em África (Carbonell, E., 2005: 62), resultante de um lento processo, profundamente associado aos períodos glaciares e interglaciares pelos quais passou o nosso planeta ${ }^{5}$.

Não podemos deixar de ressaltar a tendência que existe de generalizar conclusões para todo o conjunto do Saara, o que acaba por não dar uma imagem real da complexidade da região. Como defende Vernet, (1995: 37): "Le sahara, même dans ses périodes les plus humides, doit être envisagé non dans sa globalité, mais comme une mosaïque d'endroits privilégiés, de dimensions très variables". Tendo presente este princípio passaremos a analizar, de forma sucinta, as alterações climáticas que ocorrem no Saara, desde o Plistocénico final até à época actual, e que contribuiram, de forma decisiva, para moldar a sua fisionomia e história.

A definição do período compreendido entre os 70.000 e 40.000 BP não está isenta de polémica, uma vez que os métodos de datação não conferem até ao momento, a fiabilidade desejada (Vernet, R., 1995. 31, 46; Nantet, R., 1998: 42). Mas, o que é efectivamente aceite é que a partir dos 70.000 BP há um período relativamente árido no Saara, que corresponde ao início da glaciação de Würm na Europa, e que este período durará até aos 40.000 BP (Vernet, R., 1995: 46; Nantet, R., 1998: 41). Contudo, se bem que, durante este período, as condições não terão sido

4 As dunas, formadas por finos graõs de areia, dividem-se em activas e inactivas e dentro destas categorias existem cinco tipologias diferentes: as Whalebak (literalmente costas de baleia) são inactivas e normalmente, as mais antigas; as Bashandie ou Barchan, são dunas activas em forma de ferradura; as Seif ou dunas vivas e serpentiformes; Belts ou cinturões de dunas, imensos corredores de dunas activas; e finalmente, as Ripples, ou pequenas ondulações que muitas vezes aparecem ao lado de qualquer dos anteriores tipos de dunas (Flers, P., 2000: 144-152).

5 Referimo-nos às glaciações do período Quaternário, que se iniciaram há aproximadamente 2,5 milhões de anos e que ocorrem durante todo o Plistocénico (Vernet, R., 1995:22). 
as mais favoráveis à ocupação humana, esta estará presente e representada pelo início da chamada "civilização Ateriense". Há que referir que o Ateriense continua a ser, para muitos autores, um dos "enigmas" da arqueologia africana: "on se rend compte qu'on connaît mal le milieu, peu de chronologie et pas du tout l'origine" (Vernet, R., 2004: 93). Mas, há também quem defenda que se trata de um debate superado ( Holl, A., 2005: 7, 8), uma vez que é clara a sua definição técnica, geográfica e temporal, tratando-se de um complexo técnico datado "entre o Paleolítico Medio e o Superior, correspondendo a uma civilização que cobre todo o norte de África, desde o Atlântico até ao Vale do Nilo e do Mediterrâneo a $18^{\circ}$ de latitude norte" (Vernet, R., 2004: 93). Tecnicamente, é "uma indústria sobre lasca, produzida frequentemente pela técnica Levallois. Os utensílios compreendem fundamentalmente diferentes tipos de raspadores, denticulados, ocasionalmente utensílios do Paleolítico Superior, particularmente raspadeiras e buris, bem como peças pedunculadas e foliacias bifaciais” (Wendorf, F.; Schild, R., 1992: 50).

Esta cultura do Paleolítico do Norte de África esteve datada, até há pouco tempo, entre os 40.000 e os 20.000 BP (Vernet, R., 1995: 48) mas, actualmente, existem estações com níveis iniciais de ocupação ateriense datados entre 90.000 e 60.000 BP (Uan Afuda, no Tadrar Acacus, Líbia) ${ }^{6}$. Seja como for, este último período do Plistocénico "n'est homogène ni dans le temps ni dans l'espace" (Vernet, R., 1995: 50) e se por um lado, no Saara egípcio há indícios de um período semiárido, por outro, na Mauritânia, a presença de numerosos lagos indica que o clima seria mais húmido do que o actual. O que é aceite de forma global é que este intervalo cronológico (40.000-20.000 BP) corresponde a um período relativamente húmido, no qual se desenvolve a cultura Ateriense.

Por volta dos 20.000 BP desaparece o Ateriense, coincidindo com a última fase da glaciação de Würm na Europa e com um período muito árido, o chamado "Árido post-ateriense", que dura entre os 20.000 e os 12.000 BP. Esta época caracteriza-se pela diminuição do caudal dos grandes rios norte-africanos como o Nilo, o Senegal e o Níger, e pelo

6 Holl, A., 2005: 8. 
desaparecimento do lago Chade. "O Sahel de então transforma-se num Saara” (Nantet, B., 1998: 43). As populações dirigem-se para a periferia do deserto e neste período só o norte do Magrebe e o Vale do Nilo se mantêm habitados. É neste contexto que se dá, no Egipto, a chamada "adaptação nilótica" que consiste num nomadismo cada vez mais reduzido por parte das populações, por uma exploração intensiva dos recursos aquáticos e recoleção em grande escala de cereais selvagens (Cervelló, J., 1996: 86; Midant-Reynes, B., 1992: cap. 4). Também é deste período a necrópole de Dyebel Sahaba, no Vale do Nilo Núbio, onde pela primeira vez há indícios de violência entre grupos. Wendorf, exumou 59 esqueletos entre os quais 24 tiveram indiscutivelmente, uma morte violenta provocada por projecteis incrustados no crânio (Cervelló, J. 1993: 86; Hoffman, M., 1980: 90-99; Midant-Reynes, B., 1992: 68-69; Muzzulini, A., 1995: 46). O que provocou tal violência? Lutas pelos melhores territórios? Início de diferenciação tribal? Se tivermos em conta a exclusividade dos vestígios, verificamos que se tratou provavelmente de um acontecimento excepcional, resultante de um período no qual a pressão demográfica sobre a envolvente conduziria os grupos a situações extremas.

Com a passagem ao período Holocénico, por volta de $10.000 \mathrm{BP}$, temos uma nova fase de bonanza. O Saara volta a encher-se de vida. É o período chamado "Grande Húmido Holocénico". Para que possamos ter uma ideia da transformação que ocorre nesta época, pensemos que o lago Chade assume dimensões gigantescas alcançando a base do Tibesti (Muzzulini, A., 1995: 48). Surgem inúmeros lagos e os rios transbordam, entre eles o Nilo. É a época do "Nilo selvagem", que leva consigo os vestígos de ocupação que possam ter ocorrido no Vale do Nilo egípcio entre os 11.000 BP e os 8.000 BP. A hipótese que defende que os vestígios desse período estarão enterrados no lodo do Nilo é, sem dúvida, a mais provável, uma vez que, apesar de terem existido grupos que se deslocam de novo para o interior do deserto, é pouco provável que todo o vale do Nilo se tenha esvaziado de vida ${ }^{7}$. O que desaparece efectivamente é a "adaptação nilótica", bem como o processo que esta tinha iniciado.

7 Devemos diferenciar entre o Vale do Nilo egípcio e o Vale do Nilo sudanês, uma vez que neste último há vestígios de ocupação no Holocénico inicial (Vernet, R., 2004: 95). 
Curiosamente, é no interior do Saara que terão lugar, neste período, acontecimentos excepcionais. Surgem ocupações humanas que se estendem desde o Vale do Nilo sudanês (região de Khartoum), passando pelo deserto ocidental egípcio, até ao coração do Saara, e que estão associadas a uma economia epipaleolítica de amplo espectro (presença da caça, pesca e recolecção), com forte presença de material lítico de moagem e, o mais surpreendente, cerâmica (Cervelló, J., 1993: 87; Muzzulini, A., 1995: 48). A presença de cerâmica é surpreendente por dois motivos: por um lado, pelas datações, uma vez que temos cerâmicas datadas do IX milénio BP (fig. 2) e, por outro lado, pelo facto de serem anteriores à domesticação, o que introduz um dos temas mais debatidos na arqueologia do Saara: a utilização, ou não, do termo Neolítico, para este período. A questão que se coloca é se existe Neolítico no Saara a partir do IX milénio BP. Para os historiadores francófonos, a partir do momento em que há cerâmica, podemos falar de Neolítico. Para os anglo-saxões, não é uma questão de produção cerâmica, mas de produção alimentar, ou seja, de domesticação (Muzzulini, A., 1995: 41). Por esse motivo, há quem defenda que este período da história do Saara deveria ser denominado "Cerâmico" em vez de Neolítico (Hendrickx, S.; Vermeersch, P., 2000: 32) e quem simplesmente defenda que se trata de outro processo de neolitização diferente e anterior ao que ocorre no Próximo-Oriente, onde assistimos a um Neolítico pré-cerâmico.

A cerâmica deste período do Saara, cujas características são similares em toda a área referida, caracteriza-se por formas simples, esféricas de fundo redondo, com decoração incisa, previa à cocção, cujos motivos foram designados de Wavy-line e Dotted Wavy-line (Arkel, A., $1949)^{8}$. Friederike Jesse ${ }^{9}$, no seu magnífico livro dedicado, em grande parte, ao estudo da cerâmica de Wavy-line do Wadi Howar, conclui que existem dois focos iniciais de produção cerâmica no Norte de África, sendo provavelmente, independentes um do outro: um no Saara central (Aïr, Hoggar, Tassili e Acacus), e outro, no Vale do Nilo Núbio (região de Khartoum) e deserto ocidental do Egipto (Nabta Playa, El Adam e Bir Kiseiba).

8 Arkel, A., 1949. Early Khartoum, London: Oxford University Press.

9 Jesse, F., 2003, Rahib 80/87, Ein Wavy-Line-Fundplatz im Wadi Howar und die früheste Keramik in Nordafrika, Africa Praehistorica, 16, Köln: Heinrich Barth Institut. 
A este conjunto cultural, que ocorre durante o "Grande Húmido Holocénico", foi atribuido por G. Camps (1980) a denominação de "Neolítico Saaro-sudanês" e por Sutton (1974-77) a de "Civilização Aqualítica". Este último nome nasce da utilização que efectuam estas populações dos recursos aquáticos diponíveis, com forte presença de arpões em osso. Contudo, este conceito de "civilização aqualítica" sofreu alguma contestação, uma vez que, em palavras de Muzzulini (1995: 48): “Elle ne correspond sans doute qu'au constat de vagues similitudes technologiques et sociologiques dans l'adaptation de groupes divers à des conditions environnementales analogues".

É também durante este período, que aparecem as primeiras representações de arte rupestre do Saara. Arte que Cornevin (1982: 440) define como "o maior e mais belo museu pré-histórico do mundo". Relativamente à datação da arte rupestre saariana, questão delicada e de amplo debate, podemos destinguir duas escolas: a italiana e a francesa (fig. 3). A primeira defende cronologias altas e está representada por Mori. A segunda defende cronologias mais recentes, e o seu principal representante é Muzzulini (Aumassip, G., 1993, 4; Cervelló, J., 1993: 88; Sansoni, U., 1994: 52-53). Normalmente é divida em cinco períodos, identificados pela fauna que aparece representada, e que correspondem a diferentes "estilos". Assim, temos o Período Bubalino (ou da grande fauna selvagem), o Período das Cabeças Redondas (o mais enigmático de todos), o Período Bovidiense ou Pastoral, o Cabalino (ou do cavalo) e finalmente, o Camelino (ou do camelo).

Ao "Grande Húmido Holocénico" segue-se um período árido, relativamente curto, chamado "Árido do Holocénico médio", datado entre os 6000 BC e os 5000 BC. Apesar da sua curta duração é um período fundamental da história do Saara, uma vez que se estabelece de forma definitiva o Neolítico, com a presença da domesticação de animais e plantas. Cervelló (1993: 88) destingue quatro áreas fundamentais do Neolítico do Norte de África: área mediterrânica (Marrocos e Argélia); área Saariano-sudanesa, o Vale do Nilo egípcio e a região do Atlas e franja septentrional do Saara. Gostaríamos de referir a Saaro-Sudanesa, uma vez que é aqui que encontramos a primeira estação arqueológica do Norte de África, onde estão presentes todos os elementos que nos permitem falar de Neolítico sem ambiguidades: Nabta Playa, localizada no deserto ocidental egípcio. Aqui, desde finais do VI milénio BP, temos a presença de domesticação de ovicaprinos, de trigo e de cevada, bem 
como de estruturas de habitat mais complexas e organizadas (Hendrickx, S.; Vermersch, P., 2000: 33) A presença de cerâmica é anterior à domesticação e para a primeira fase do processo de Neolitização das Playas há cerâmica datada de $8.100 \mathrm{BP}^{10}$. Por tudo isto, Nabta Playa, é considerada a primeira aldeia neolítica do deserto ocidental do Egipto (Midant-Reynes, B., 2003: 238).

Por volta dos $5000 \mathrm{BP}$, tem início a última grande fase benigna do Saara a do "Húmido Neolítico". No Vale do Nilo, voltamos a ter vestígios arqueológicos. Surgem as ocupações do Fayum e de Merimde e pela primeira vez podemos falar de agricultura no Vale do Nilo. Estamos perante culturas cujas raízes se encontram no Neolítico final do deserto ocidental do Egipto (Nabta Playa). Posteriormente, surgem as culturas pré-dinásticas de El-Omari e Maadi, no Norte (Baixo Egipto) e as de Badari e Nagada no Sul (Alto Egipto). A partir desde momento, nesta região de África, inicia-se um processo que levará, por volta dos $3.000 \mathrm{BP}$ ao aparecimento de uma das mais extraordinárias civilizações da história da humanidade: o Egipto faraónico.

Em 2.500 BP, aproximadamente, inicia-se o processo de desertificação que dura até aos nossos dias. O Saara não voltou a ter épocas de bonanza. Poco a pouco, foi-se transformando naquilo que é hoje. Mas, o que está claro, é que se o deserto do Saara nunca esteve totalmente desabitado (actualmente continua a ser cruzado por nómadas, sobretudo na região do Saara mauritano), o que é certo é que a sua história está profundamente associada a essas oscilações e mudanças climáticas que assolaram a região. O Homem tentou sempre adaptar-se e a introdução do camelo permitiu que, em pleno período de desertificação e abandono, o homem voltasse a cruzar o deserto de sul a norte transportando mercadorias da África negra para o mundo mediterránico e vice-versa, dando origem às famosas rotas trans-saarianas da época medieval.

Mas, como influem as questões climáticas e de outros âmbitos, na arqueologia do Saara? Com que problemas se depara um arqueólogo que trabalhe nessa região do planeta, e quais são as problemáticas actuais da arqueologia no Saara?

10 Wendorf, F.; Schild, R., 1980: 301.

Conimbriga, 45 (2006) 359-375 
Para começar não podemos deixar de ter presente algo que já referimos anteriormente: o imenso território que abarca o Saara, com aproximadamente, 8.000.000 km2. Desta superficie apenas uma ínfima parte foi estudada e, por esse motivo, é tão difícil fazer uma síntese ou inclusive comparar regiões. Apesar disso, nas últimas décadas ${ }^{11} \mathrm{o}$ interesse pela pré-história do Saara tem aumentado e começa a ser possível aceder a obras que nos dão uma imagem se não global, pelo menos regional (Heinrich Barth Institut, 2002; Klees, F.; Kuper, R., 1990; Midant-Reynes, B., 1992; Vernet, R., 2000). As regiões mais estudadas do Norte de África, são o Vale do Nilo, o deserto ocidental do Egipto, os maciços montanhosos do Saara central, a região do Dhar Tichitt-Walata (Mauritânia), a região do lago Chade, e algumas regiões de Marrocos (Vernet, R., 1993).

É claro que com isto não queremos dizer que, se há regiões que não estão estudadas, é por falta de interesse por parte dos investigadores! É muito mais complexo do que isso. Há dificuldades de vários tipos, por exemplo, ambientais e económicas. Trabalhar numa região como o Saara implica trabalhar em condições extremas, não só físicas como também psicológicas e sobretodo, implica um custo económico muitas vezes difícil de assumir ${ }^{12}$. Não podemos esquecer que alguns

11 A investigação sobre a pré-história do Saara está profundamente relacionada com o crescente interesse demonstrado, a partir dos anos 60 do século passado, pelas culturas pré-históricas do Vale do Nilo Núbio. Este interesse nasce com a construção da barragem de Assuão no Egipto, quando a UNESCO promove uma campanha de salvamento dos monumentos da Núbia. As equipas multidisciplinares que se formam vão descobrir a riqueza pré-histórica que antecede o nascimento da cultura faraónica. Por outro lado, a pré-história do Saara também está profundamente associada à descoberta da arte rupestre da região. Quando Henri Lothe publica em 1958 a sua obra, A la découverte des fresques $d u$ Tassili, traz à luz um mundo insuspeitado e de uma beleza avassaladora, que fascinará as futuras gerações de investigadores.

12 Contudo, devemos assinalar que nem sempre é só uma questão de dinheiro, mas também de mentalidade. É, indiscutivelmente, uma questão de dinheiro para os países e investigadores norte africanos, uma vez que têm tantas necesidades básicas por cobrir, que o dinheiro para a investigação é algo absolutamente secundário. Mas, o número de equipas estrangeiras a investigar em África tem aumentado nos últimos anos e isso sim, é uma questão de mentalidade. Por exemplo, uma das melhores equipas a trabalhar no deserto ocidental do Egipto, é a do Henrich Barth Institut, da Universidade de Colónia, Alemanha. E outra das equipas com mais tradição e obra reconhecida, a favor da arqueologia do Norte de África, é a do Museo de Poznan, na Polónia. Dois países 
dos países que integram o Saara, têm ou tiveram conflitos bélicos e isso, obviamente, impediu, e ainda impede, investigar nos seus territórios (há regiões do Saara com campos de minas mal assinalados e há zonas de fronteira extremamente perigosas, como por exemplo, a fronteira do Egipto com a Líbia, que é considerada zona militar e a fronteira entre Marrocos e a Mauritânia, onde existem vários campos de minas da guerra do Saara Ocidental).

O colonialismo e as consequências que daí resultaram, também não podem ser obviadas. Actualmente, já se fala de um Neolítico que nasce no coração do Saara, em definitivo, no coração de África. Já não se procuram respostas difusionistas para explicar as inovações tecnológicas que ocorrem nessa região do planeta. Obviamente não se negam os contactos e relações que tenham existido com outras regiões ${ }^{13}$, mas África já não é o continente sem história, como o definia Westerman nos anos 30, o continente que só recebe sem contribuir com nada para a história da humanidade. Estas atitudes de superioridade dificultaram, em muito, a aceitação de que África não só tem um papel na história da humanidade, como é o berço da humanidade. Para além disso, contribuíram para que a partir da década de 60, quando se inicia o processo de descolonização em África, se tenha muitas vezes caído no outro extremo, como forma de afirmação da identidade nacional. Houve países como o Zimbabwe ${ }^{14}$, antiga Rodésia, que chegaram mesmo a expulsar os investigadores não africanos, com a convicção de que não poderiam entender a história do seu país. Em Dakar, nasce a Escola de Cheikh Anta Diop defendendo, entre outras coisas, uma africanidade

com condições económicas muito diferentes mas com uma mentalidade e políticas culturais parecidas.

$13 \mathrm{O}$ caso do Antigo Egipto é um dos mais evidentes. Durante muito tempo a civilização egípcia não foi considerada uma civilização africana (sobre as questões relacionadas com a africanidade do Antigo Egipto ver: Cervelló, J., 1993). Actualmente, sem que se negue o papel que desempenham as três regiões das quais faz parte (o mundo mediterrânico, o próximo-oriental e o africano), a civilização egípcia é considerada uma civilização cujas raízes se encontram nas culturas neolíticas do Vale do Nilo núbio e do deserto ocidental do Egipto.

14 Zimbabwe é o nome do monumento arqueológico mais importante deste país africano, que significa "casa de pedra" e que, em 1983, passa a denominar todo o país. 
racial (para além de cultural) para o Antigo Egipto. A defesa que Diop (tal como os seus sucessores) pretendia fazer das culturas africanas acabou por conduzir a extremos que levaram a que, no mundo da egiptologia tradicional (leia-se europeia), falar de um Egipto africano, ainda que num sentido cultural, remetesse imediatamente para a Escola de Dakar, com tudo o que está implicasse. Contudo, há que referir que Diop teve um papel importante ao questionar a visão difusionista próximo-oriental vigente.

Mas, o que de facto é mais problemático para os investigadores do Saara actual, são as questões metodológicas. As estações de superfície ${ }^{15}$ e a falta de estratigrafia daí resultante, colocam problemas de díficil resolução. Para um arqueológo que se dedique, por exemplo, ao período medieval europeu, pode parecer que é uma sorte que as estações se encontrem à superficie, com todos os materiais prontos a serem recolhidos. O problema é que muitas vezes não são os arqueólogos quem os recolhem. Cada dia que passa há mais turistas a viajar ao deserto, trazendo com eles muito material arqueológico que, estando à superfície, poderá parecer pouco importante. O problema é que não há outro material! Não é que o que está à superficie esteja decontextualizado, como poderia acontecer noutras regiões ou épocas. Trata-se do único contexto que existe. Há que sensibilizar o turista que vai de viagem, em busca de aventura e destinos exóticos, que não traga um souvenir, mas isso é algo extremamente dificill ${ }^{16}$. Pode pensar-se que é um exagero, e que com certeza não é um fenómeno tão grave. Mas, só para o caso mauritano os números falam por si: "centenas de milhares de pontas de flecha - as chifras são seguras - desapareceram durante o século XX levadas para a Europa, onde dormem dentro de gavetas esquecidas". (Vernet, R.; Mohammed Naffé, B., 2003, Diccionnaire Archéologique de la Mauritanie, Nouakchott: CRIA: 9). O património mauritano e o do Saara está realmente em risco. Os próprios nómadas recolhem o material para ven-

15 Existem algumas estações com estratigrafia, mas são a infinita minoria. Temos por exemplo as estações de Uan Muhuggiag (Acacus, Líbia); Tin Torha (Acacus, Líbia), Tin Hanakaten (Tassili, Argélia).

16 Actualmente existem campanhas de sensibilização para os turistas que viajam ao Saara, para que não tragam objectos arqueológicos, não toquem nem molhem as pinturas rupestres para fazer melhores fotos, que não tragam espécies vivas (animais ou plantas) e que tragam de volta todo o lixo que façam no deserto. 
der aos turistas ${ }^{17}$. Trata-se de um caso alarmante de tráfico de antiguidades muito díficil de travar, uma vez que é quem viaja que tem de ser responsável e respeitar o património que encontra. No Egipto, depois de décadas de pilhagem, as autoridades assumiram a responsabilidade que têm sobre o seu património; hoje, a pilhagem de material arqueológico é punível com pena de prisão efectiva. Esperemos que nos outros países do Saara estas medidas cheguem depressa e que não seja demasiado tarde.

Para além destas questões, há outra relacionada com a metodologia a aplicar nas estações de superficie. Actualmente, considera-se que se deve tentar fazer são mapas da superfície que recolham todo o material, para que se possa ter uma visão horizontal e de conjunto. Teremos mapas de distribuição espacial, mais do que temporal. Mas é fundamental fazer esta cartografia de superfície, uma vez que o mais habitual no Saara é encontrar, à superficie e muitas vezes a poucos metros, como em Khatt Lemaiteg (Mauritânia): "um biface acheulense do neolítico recente (...), objetos em bronze e uma ponta de lança em ferro, uma mó giratória medieval, um cachimbo de terra cozida e fragmentos de caixas de chá e conservas abandonadas pelos turistas, completam a cronologia do sitio" (Vernet, R., 1993: 206). O mais importante é que os investigadores que trabalham no Saara, sigam uma metodologia mais ou menos homogénea para toda a região. De facto, tal como Vernet (1993: 207), pensamos que é possível encontrar essa metodologia comum, uma vez que a ocupação humana do deserto do Saara é bastante homogénea e as actividades realizadas, do Atlântico ao Mar Vermelho são muito parecidas. É claro que cada estação é um mundo, mas vários investigadores uniram-se para publicar um manual básico de arqueologia no Saara, que pretende uniformizar, na medida do possível, métodos e técnicas ${ }^{18}$.

17 Às vezes também o recolhem para uso próprio, como no caso das mós neolíticas que continuam a ser utilizadas pelas famílias nómadas que cruzam o deserto. Pensamos que essa reutilização do material arqueológico é, claramente, menos grave e em todo o caso, em menor número.

18 CNRS, Groupement de recherche 0848, 1995, Méthodes d'Aproche de la Préhistoire Saharienne. Les gisements: reconnaissance et exploitation, Paris, Alger et Tunis: CNRS, Éditions Bouchene et Alif. 
Para terminar, gostaria apenas de referir que o Saara é uma imensa estação arqueológica, muito frágil, que merece ser estudada e conhecida. Há muito por fazer. Existem várias questões em aberto, como por exemplo, as relacionadas com a cronologia e o estudo da arte rupestre saariana. Mas pensamos que a melhor forma de respeitar o Saara, a sua história passada e as culturas que actualmente continuam a povoá-lo, é conhecendo-o. Por isso, pensamos que é fundamental que, tanto em África como na Europa, se formem investigadores especializados para trabalhar nesta região, cujo património é, afinal, reponsabilidade de todos.

\section{BIBLIOGRAFIA:}

Almásy, L. E., 1999, Nadadores en el desierto. A la búsqueda del oasis de Zarzura, Barcelona: Península, Altair viajes, 13.

Aumassip, G., 1993, Chronologies de l'art rupestre saharien et Nord Africain, Jacques Gandini.

Aumassip, G.; Desmond Clark, J.; Mori, F. (eds.), 1996, The Prehistory of Africa. The Concept of the "Neolithic" in Africa with Particular Reference to the Sahara Region. Colloquium XXX. International Union of Prehistoric and Protohistoric Sciences. ABACO Edizioni: 219-239.

Carbonell, E. (coord.), 2005. Homínidos: las primeras ocupaciones de los continentes, Barcelona: Ariel.

Cervelló, J., (1995), Las Raíces Africanas de la Civilización Faraónica”, in Revista de Arqueología, 174: 22-33.

1996, Egipto y África. Origen de la civilización y la monarquía faraónicas en su contexto africano, Sabadell: Ausa, Aula Orientalis-Supplementa, 13.

, 2001, África Antiga. El Antiguo Egipto, una civilización Africana. Actas de la IX semana de estudios africanos del Centre d'Estudis Africans de Barcelona. Barcelona: Aula Aegyptica Studia.

CNRS, GROUPEMENT DE RECHERCHE 0848, 1995, Méthodes d'Aproche de la Préhistoire Saharienne. Les gisements: reconnaissance et exploitation, Paris, Alger et Tunis: CNRS, Éditions Bouchene et Alif.

Coulson, D.; Campbell, A., 2001, African Rock Art. Paintings and engravings on stone, New York: Abrams.

Durou, J.-M., 1993, L'exploration du Sahara, Paris: Terres d'Aventure/ Actes Sud. 1997, Le grad rêve saharien, Paris: Actes Sud.

Flers, P., 2000, Egypt civilization in the Sands, Cologne: Könemann.

Fonseca Braga, S., (1999), "Evidências do substrato cultural norte-africano no Antigo Egipto, no Saara pré-histórico e na África actual”, In Arqueologia, 24: 111-120. 
(2002), "Egipto um oásis do Sara", In Hathor estudos de egiptologia, 5 Lisboa, Associação Portuguesa de Egiptologia, 5: 11-21.

Hachid, M., 1998, Le Tassili des Ajjer. Aux sources de l'Afrique 50 siècles avant des Pirámides, Paris: Paris - Méditerranée.

HeInRICh Barth Institut, 2002, Tides of the Desert. Contribuitions to the Archaeology and Environmental History of Africa in Honor of Rudolph Kuper, Cologne, Heinrich Barth Institut, Africa Praehistorica, 14.

Hendrickx, S.; Vermersch, P., 2000, "Prehistory. From the Palaeolithic to the Badarian Culture (c. 7000,000 - 4000 BC)". In Shaw, I., The Oxford History of Ancient Egypt, Oxford University Press.

Hoffman, M., 1980, Egypt Before the Pharaohs. The prehistoric Foundations of Egyptian Civilization, New York: Dorset press.

Holl, A., (2005), "Breve histoire d'un concept: le Débat Atérien, In Sahara, 16: 7-26. (2005), "Holocene "Aquatic" Adaptation in North Tropical Africa", in Stahl, A. (ed.), African Archaeology. A Critical Introduction, Blackwell Publishing. Hugot, H. J.; Bruggmann, M., 1999, Sahara art rupestre, Les Editions de l'Amateur. KleEs, F.; KuPer, R., 1990, New Light on the Northeast African Past. Current Prehistoric Research, Cologne, Heinrich Barth Institut, Africa Praehistorica, 5.

Jesse, F., 2003, Rahib 80/87, Ein Wavy-Line-Fundplatz im Wadi Howar und die früheste Keramik in Nordafrika, Africa Praehistorica, 16, Köln: Heinrich Barth Institut.

Le-Quellec, J.-L., 1998, Art rupestre et préhistoire du Sahara, Paris, Bibliothèque Payot.

Midant-Reynes, B., 1992, Préhistoire de l'Egypte. Des premiers Hommes aux premiers Pharaons. Paris: Armand Colin.

2003, Aux Origines de l'Égypte. Du Néolithique à l'émergence de l'État, Fayard,

Monod, Th., 1998, O Explorador do Absoluto, Lisboa: Publicações Europa-América. 1999, Camelladas. Exploraciones por el verdadero Sáhara, Barcelona: Terra Incógnita

Muzzolini, A., 1995, Les Images rupestres du Sahara, Toulouse: Edite par l'auteur, Préhistoire du Sahara 1.

Nantet, B., 1998, L'invention du desert. Archéologie au Sahara, Paris: Voyageurs Payot..

1999, Dictionnaire d'Histoire et Civilisations africaines, Paris: Larousse.

SAnsoni, U., 1994, Le più antiche pitture del Sahara, L'Arte delle Teste Rotonde. Jaca Book.

SERS, J.-F., 1994, Désert Libique, Paris: Editions Arthaud.

Vaes, B.; Marmol, G.; D’Otreppe, 2000, Sahara, Guides Bleus Évasion, Toulouse, Hachette.

VERnET, R., (1993), “L'objet Archéologique et les sites de surface dans le sud du Sahara et le Sahel”. In L'objet archéologique africain et son devenir. Paris: CNRS: 203-214. 1995, Climats Anciens du Nord de l'Afrique. Paris: L'Harmattan. 2000, L'Archéologie en Afrique de l'Ouest. Sahara et Sahel, Nouakchott: CRIAA - Editions Sépia. 
, (2004), "Le Sahara préhistorique entre Afrique du Nord et Sahel: état des connaissances et perspectives", in Bazzana, A.; Bocoum, H., 2004, Du Nord su Sud du Sahara. Cinquante ans d'archéologie française en Afrique de l'Ouest et au Magreb. Bilan et perspectives, Paris: Éditions Sépia: 89-100.

Vivian, C., 2000, The Western Desert of Egypt, Cairo: The American University in Cairo Press.

Wendorf, F.; Schild, R., 1992, "The Middle Paleolithic of North Africa: a Status Report. In Kupper, Rudolph (ed.) New Light on the Northeast African Past, Köln: Heinrich Barth Institut. (ed.), 1980, Prehistory of the Eastern Sahara. Academic Press. 
EST. I

ธ



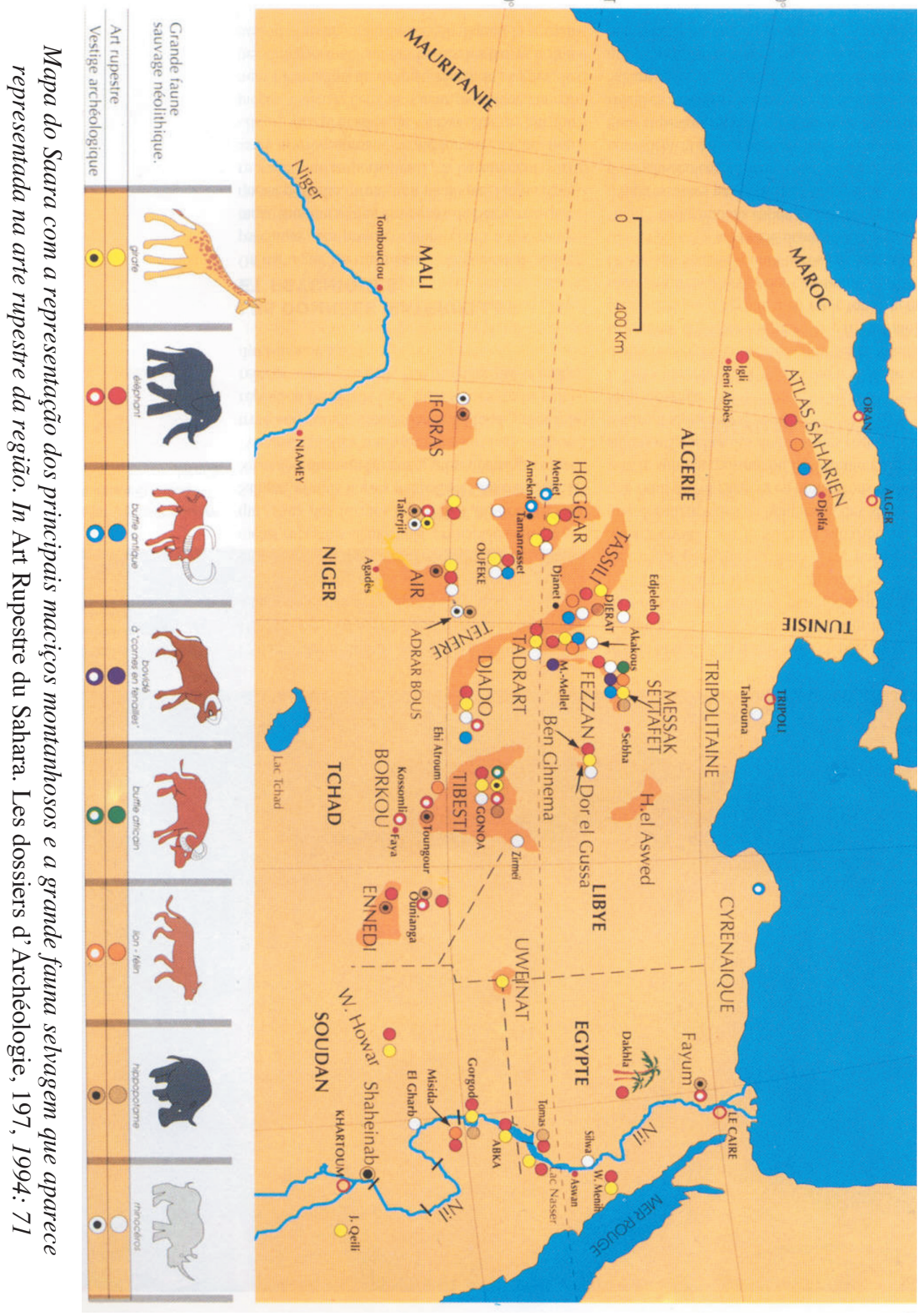


Est. II
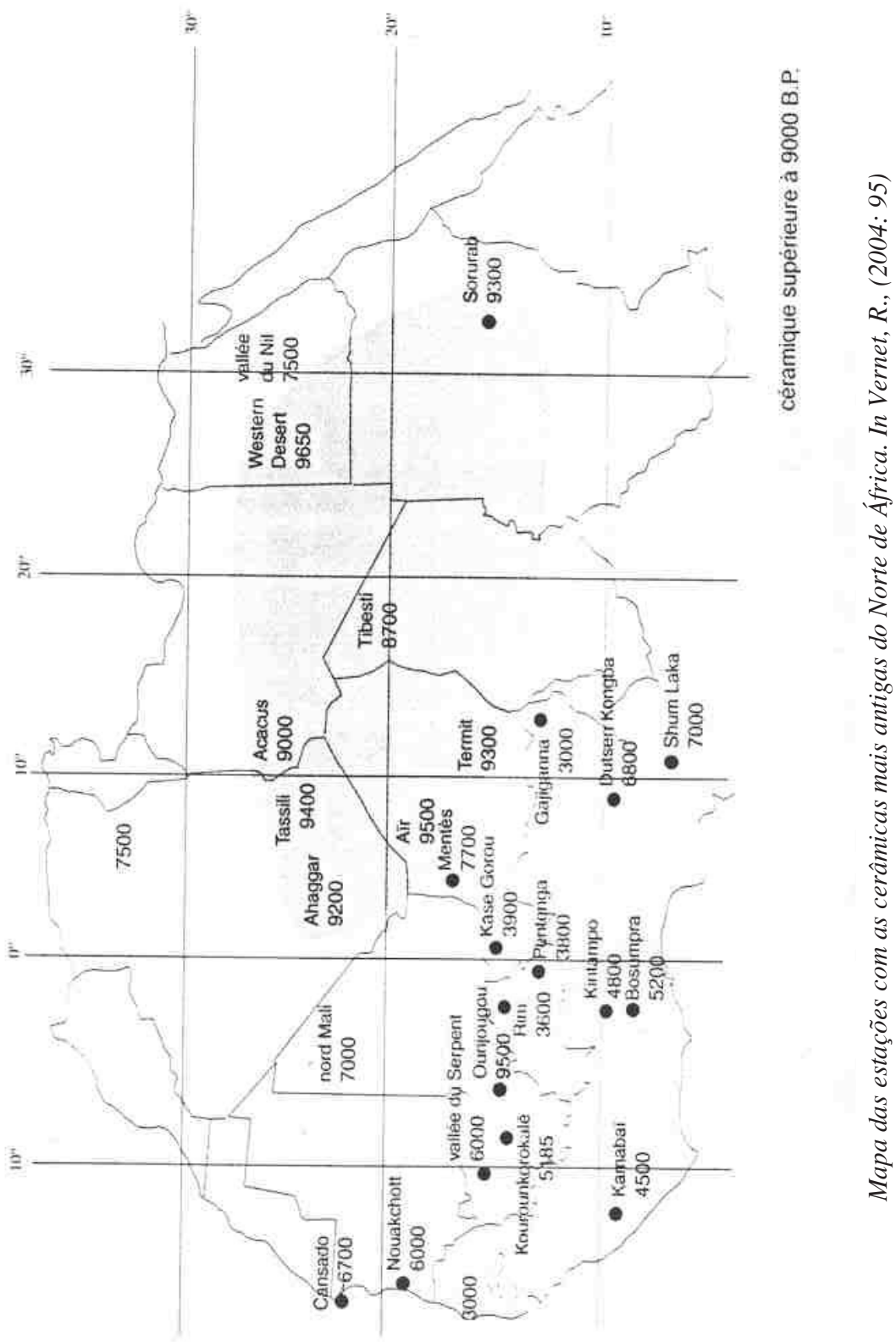


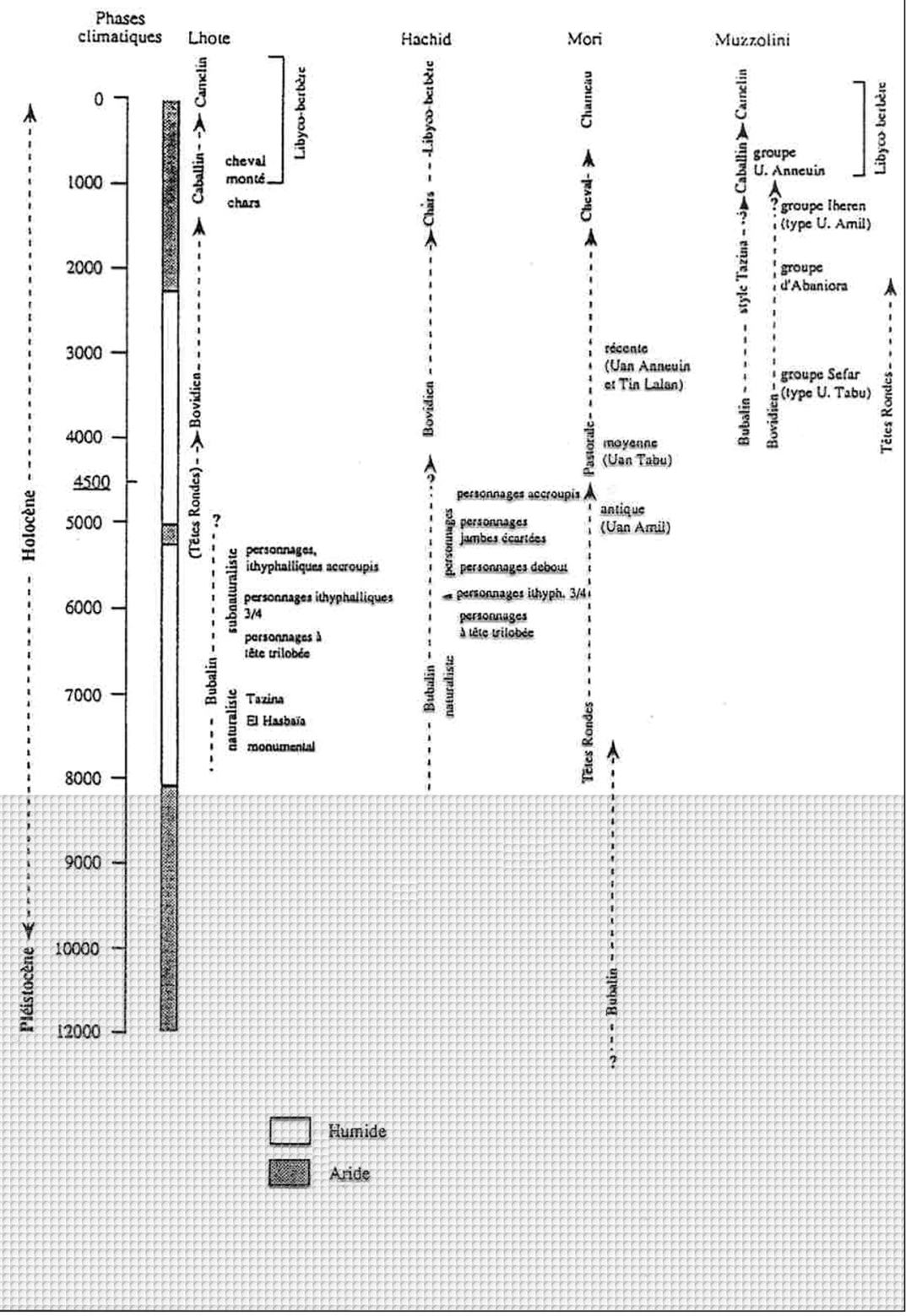

Cronologia comparada da arte rupestre do Saara. In Aumassip, G., 1993: 4 